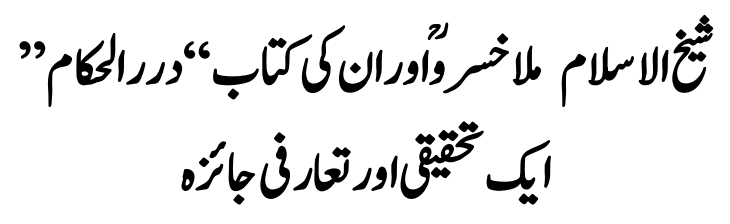

\title{
Sheikh al-Islam Mulla Khusro and his Book \\ "Durar al Hukkam": An Analytical and Introductory Review
}

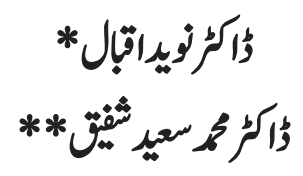

\begin{abstract}
Mulla Khusro was one of the most famous and intelligent scholars of Ottoman era. In the $14^{\text {th }}$ century during the era of Caliphate Murat II, he completed the religious education and started teaching in Shah Malik Madrasa. He also worked as mufti and Qazi (justice) in different cities after serving in the army as teacher and Qazi for many years. He is not only known as Qazi or mufti but is also for being sheikh ul Islam. He is also famous for writing several books about Arabic Language, fiqh (jurisprudence), Principles of Islamic jurisprudence and literature. His most famous book is Durar al Hukkam in which he reviewed the problems related to justice affairs. Later, Qazi (justice) used to refer to this book in matters of dispute. In this paper we will discuss briefly the life of Mulla Khusro and the place of his book in the Ottoman era. The topic is mostly written in the Turkish language so we will be focusing on such references.
\end{abstract}

Key Words: Mulla Khusro, Ottoman Era, Durar al Hukkam, Book Value Introductory Review

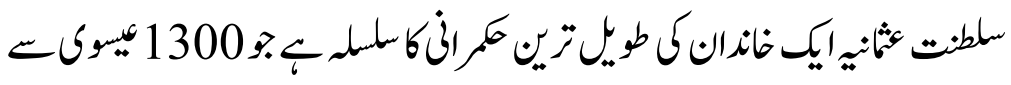

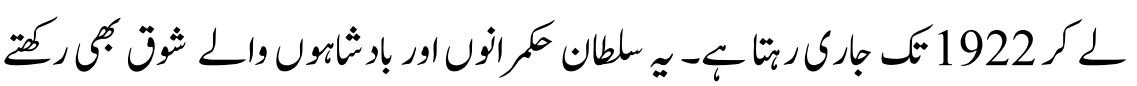

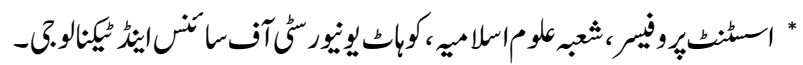

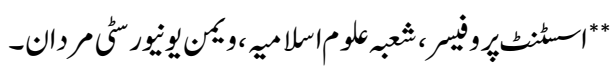




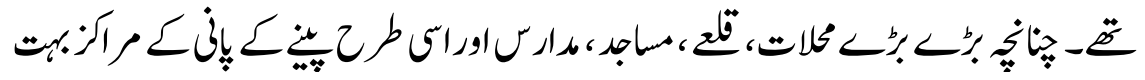

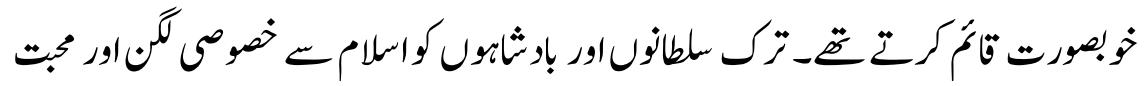

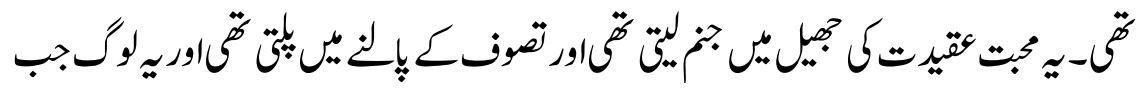

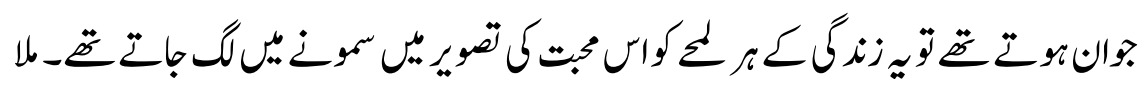

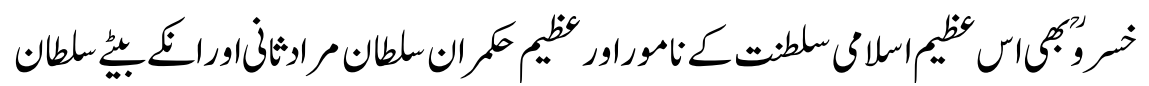

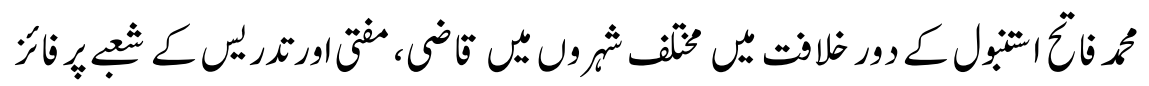

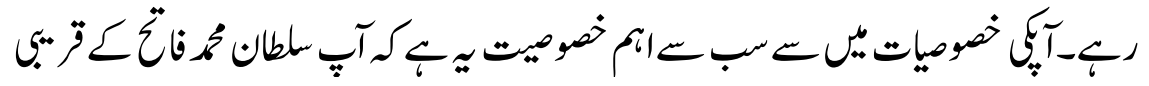

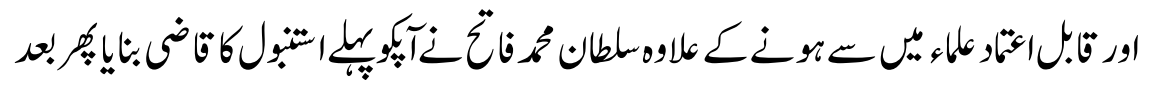

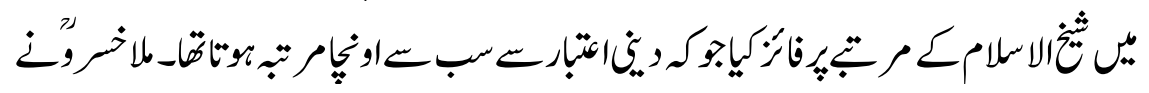

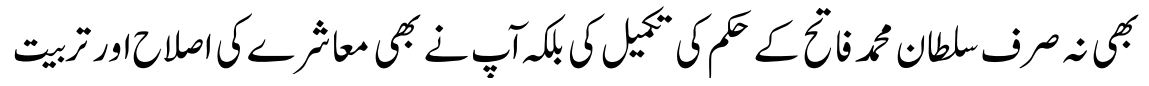

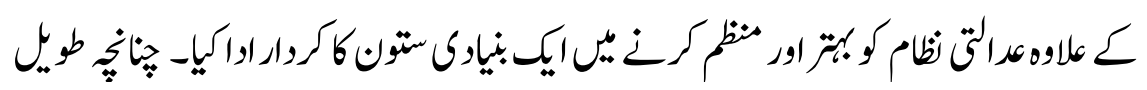

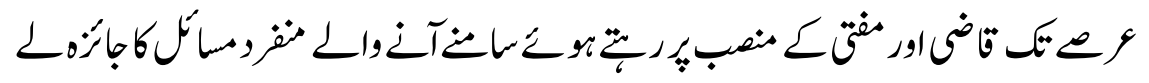

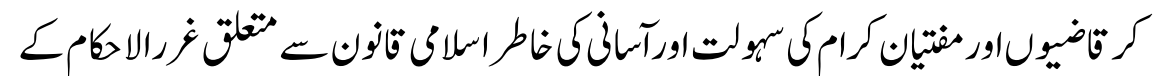

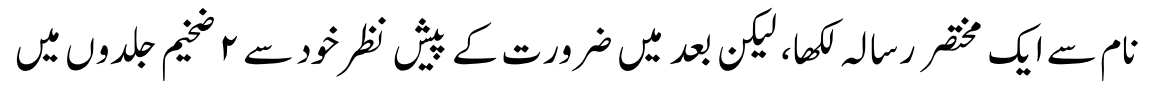

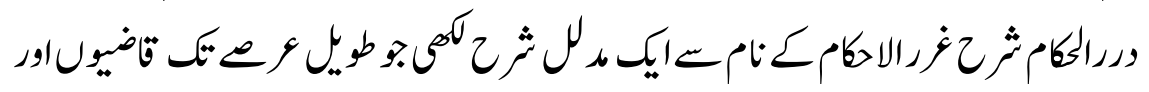

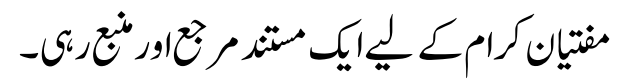

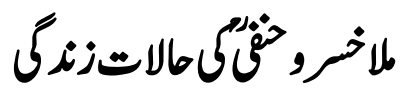

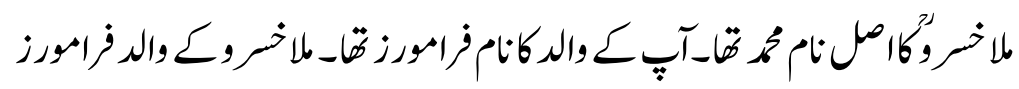

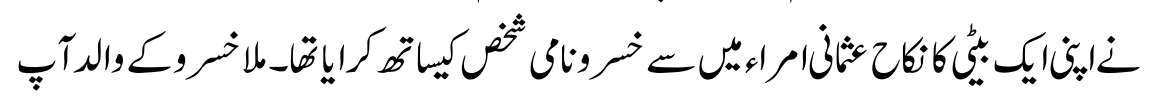

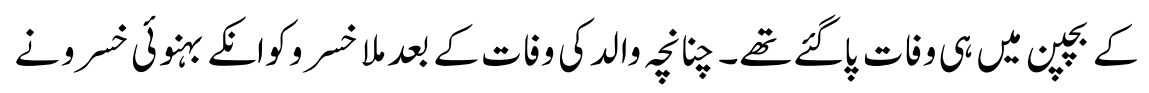




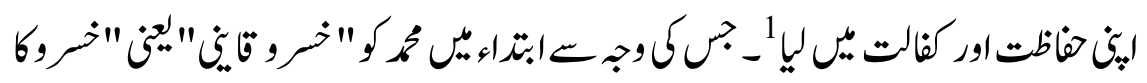

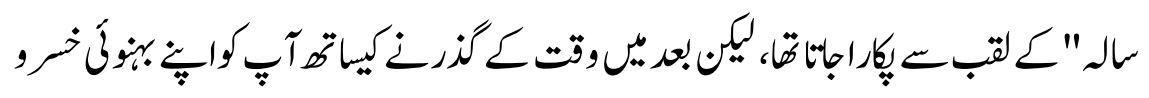

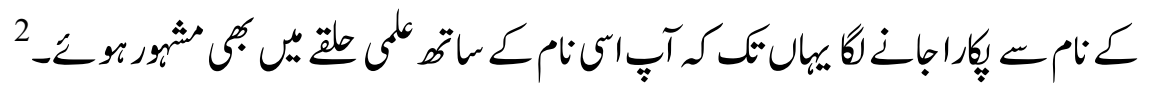

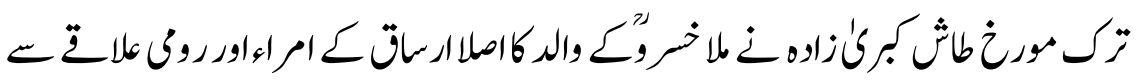

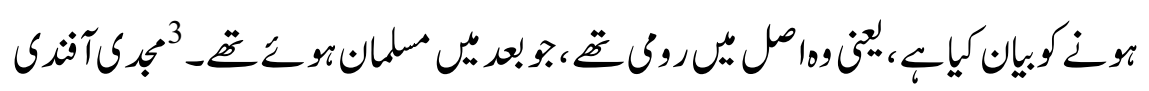

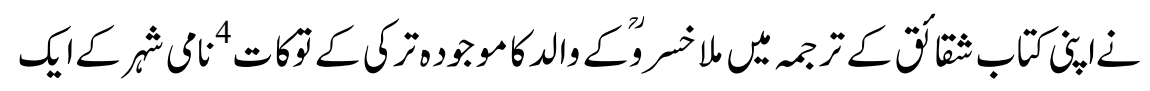

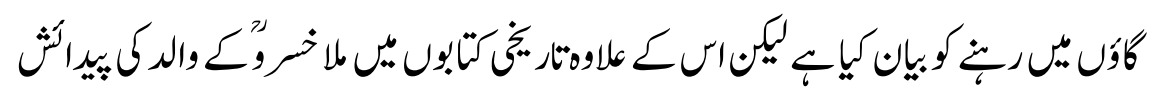

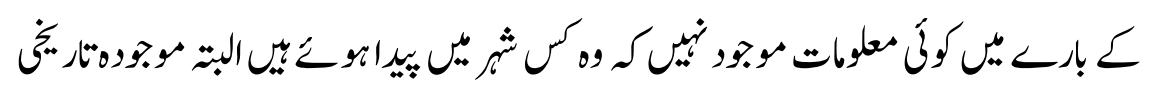

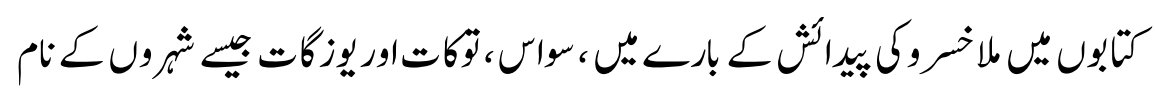
كتئيس

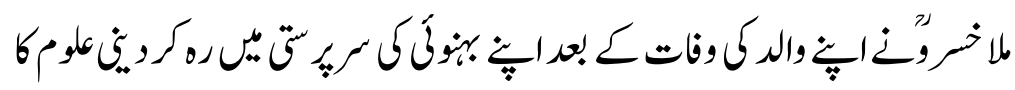

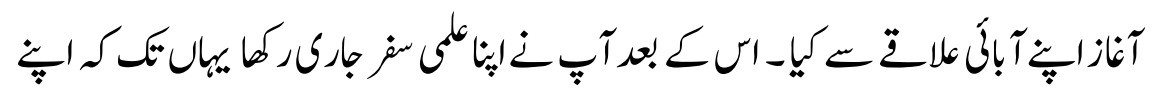

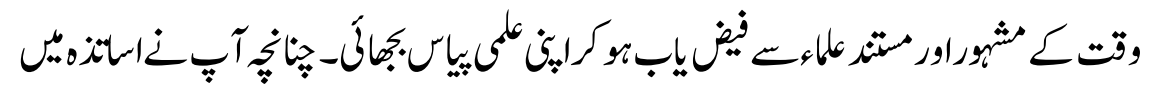

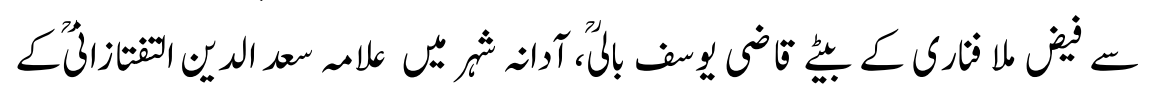

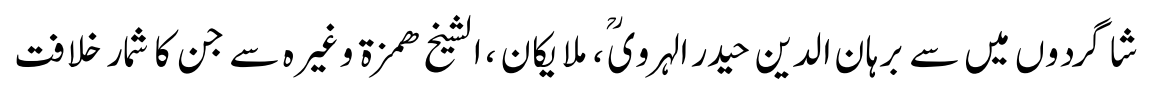

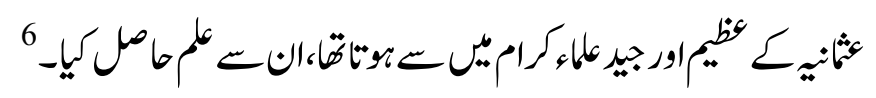

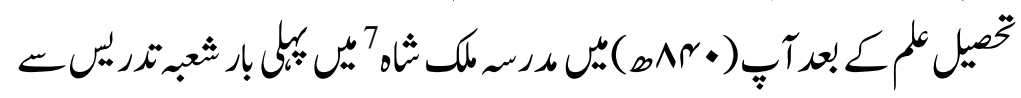

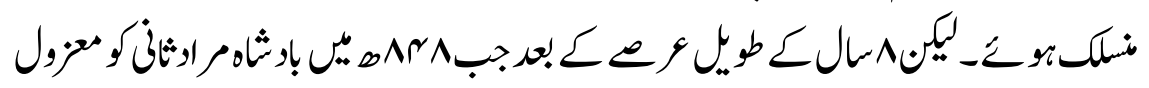

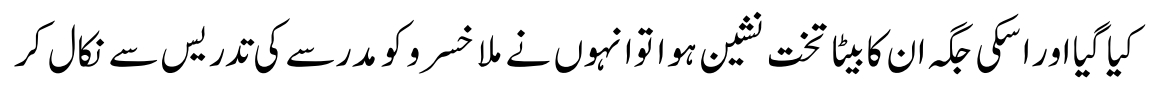

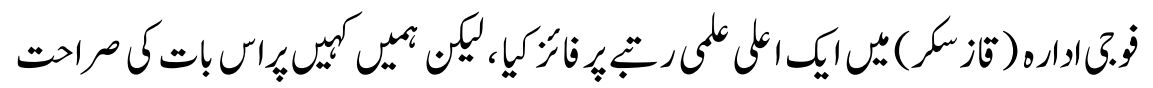

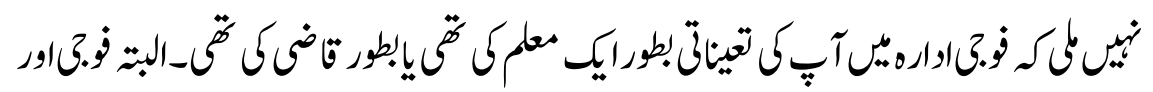




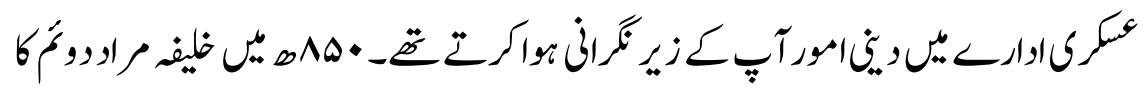

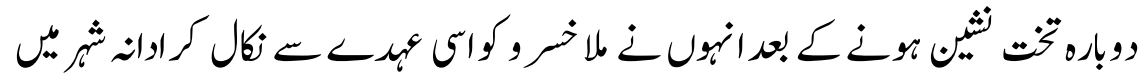

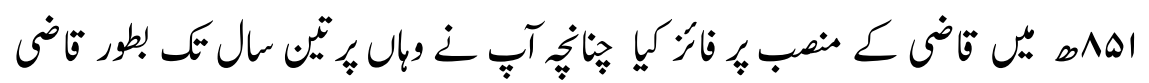

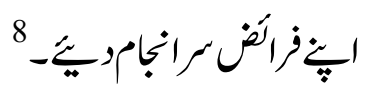

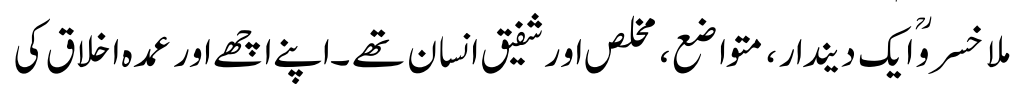

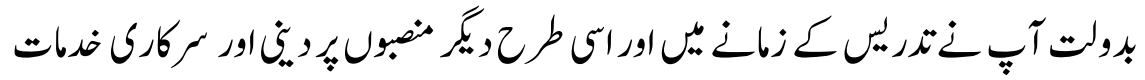

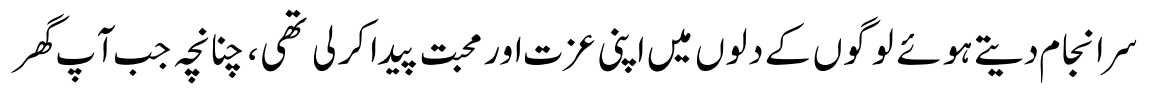

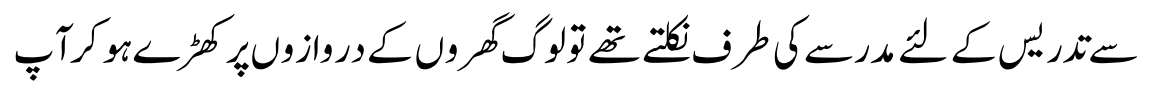

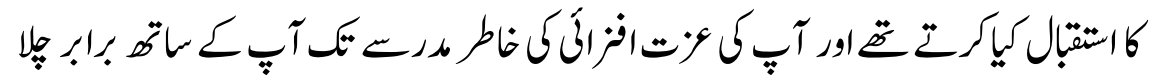
كرتح

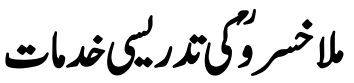

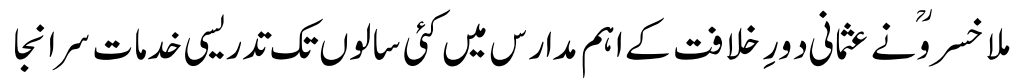

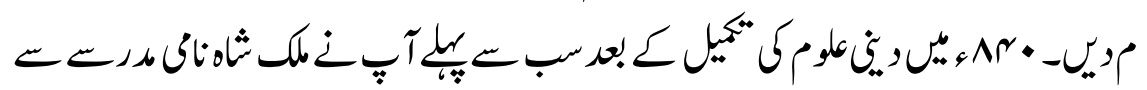

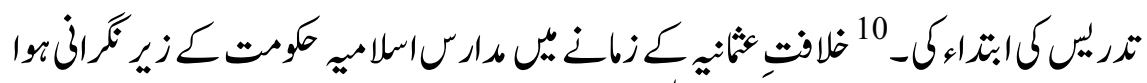

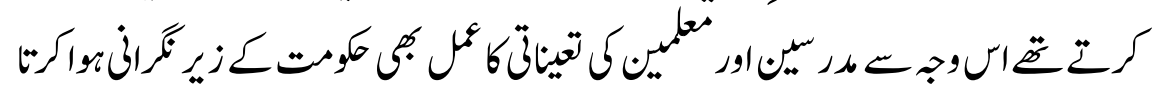

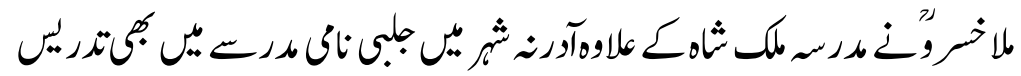

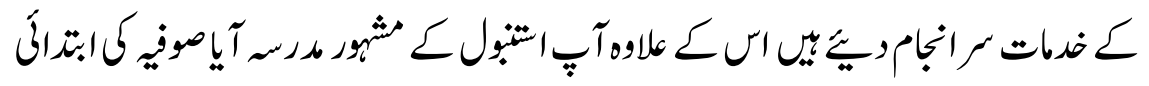

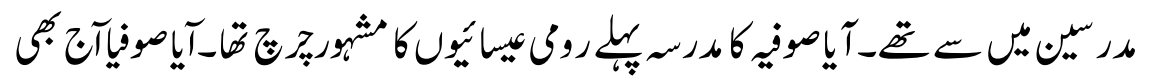

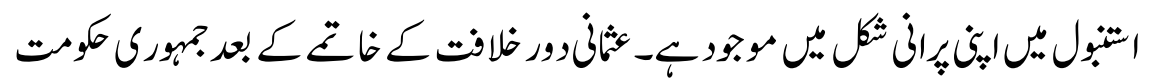

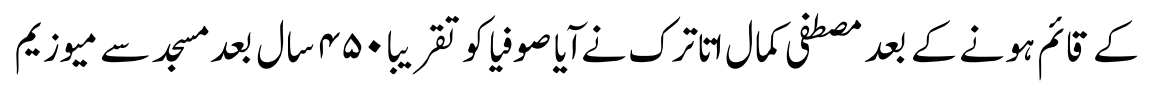




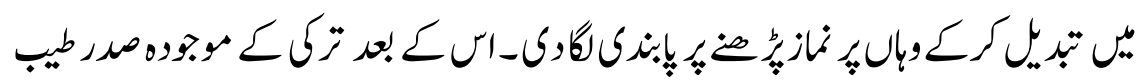

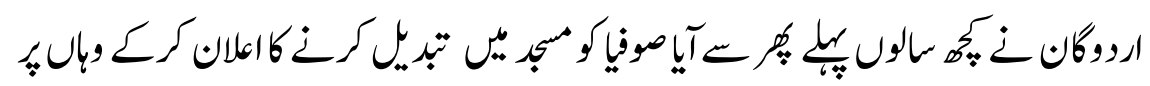

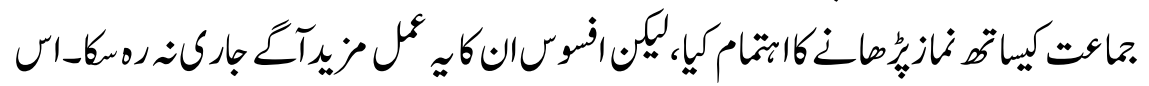

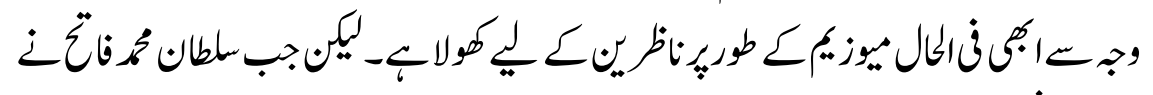
استنولفنكيا-

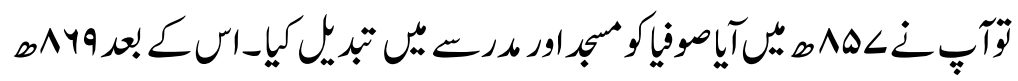

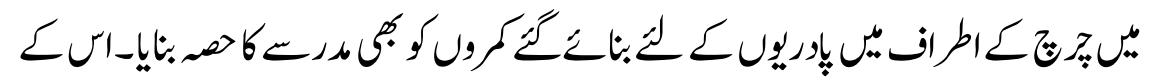

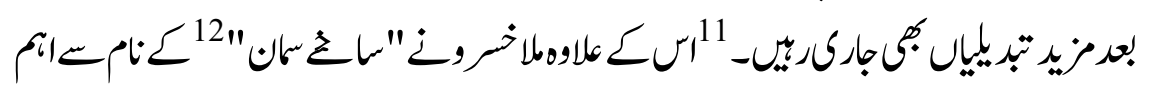

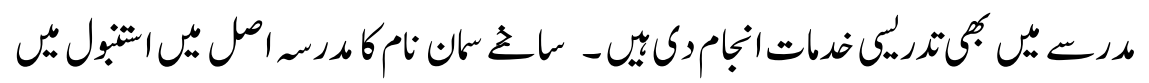

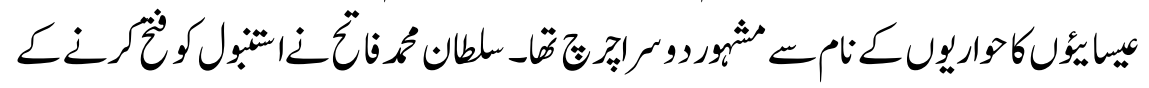

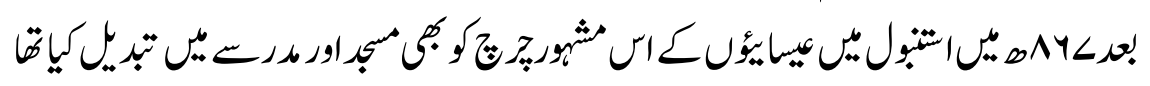

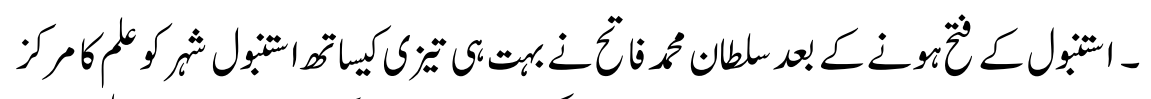

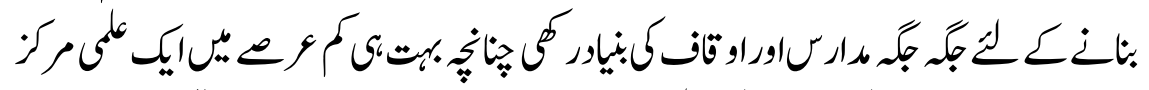

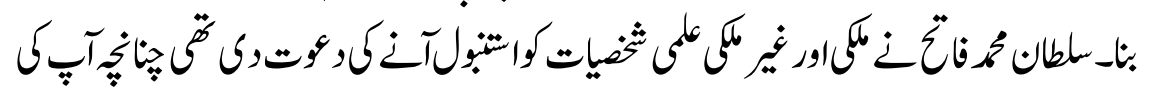

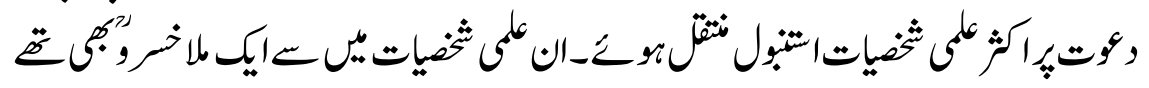

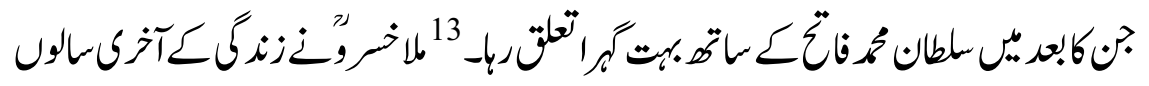

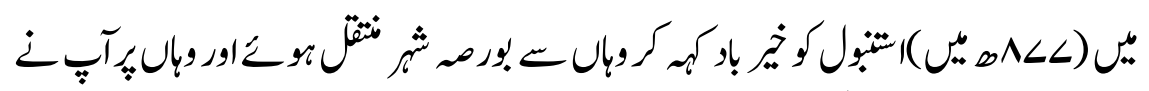

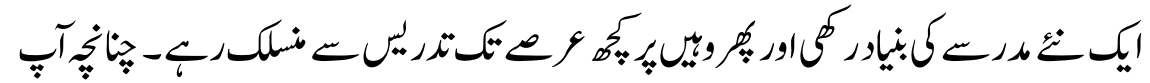

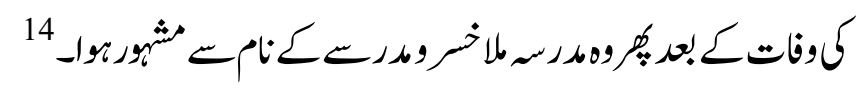

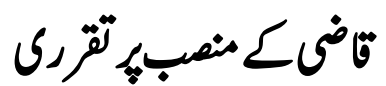

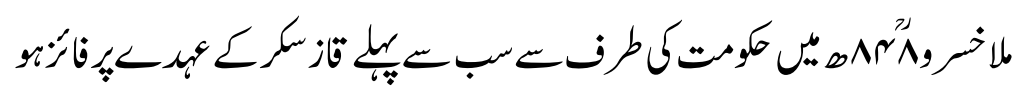

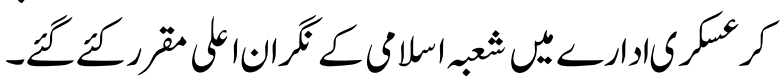




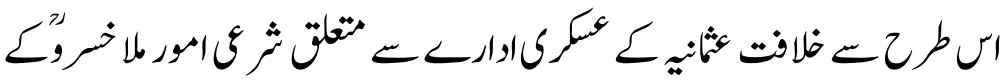

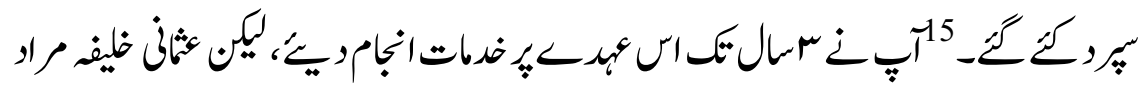

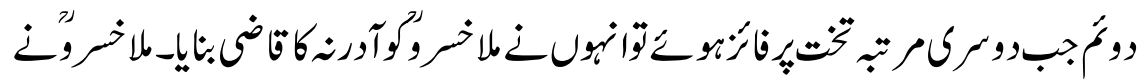

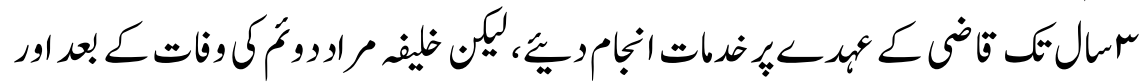

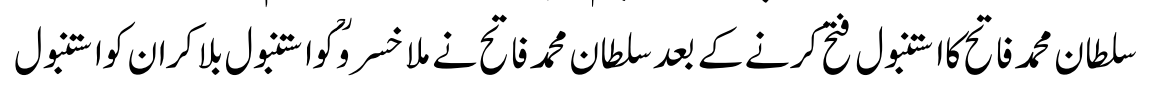

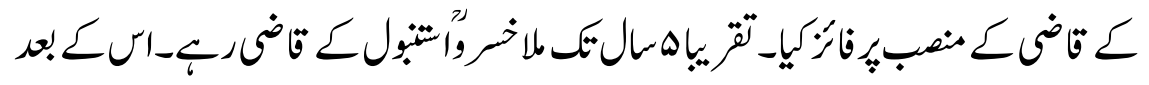

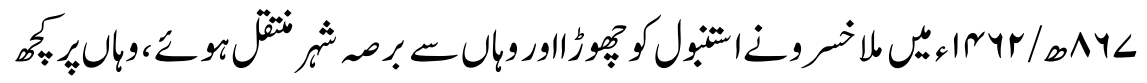

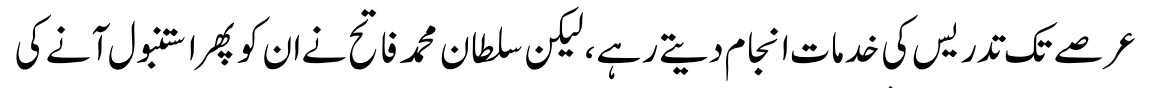

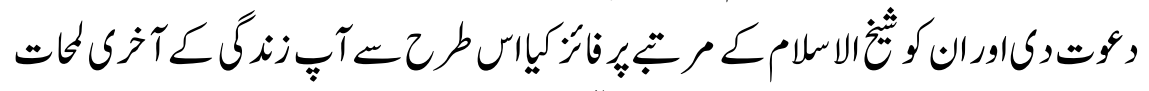

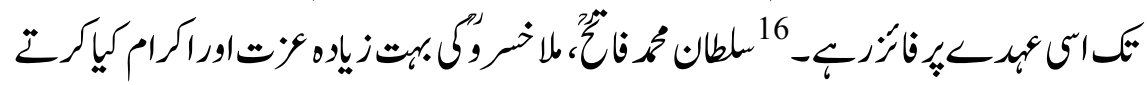

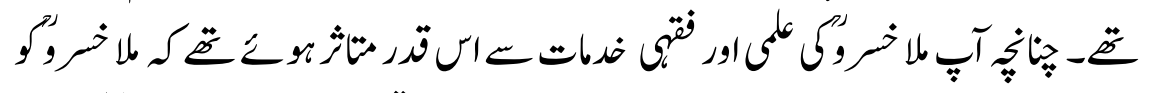

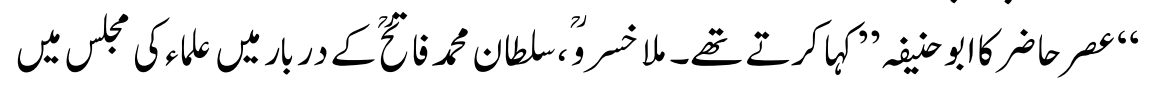

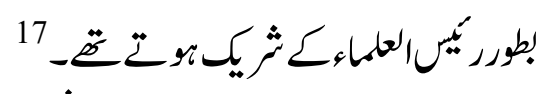

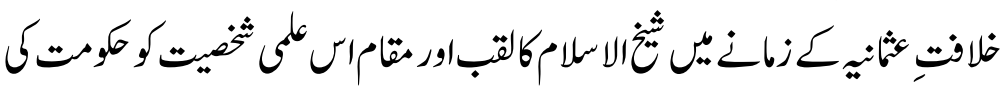

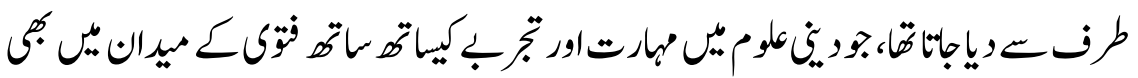

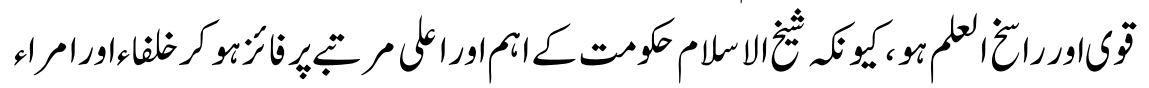

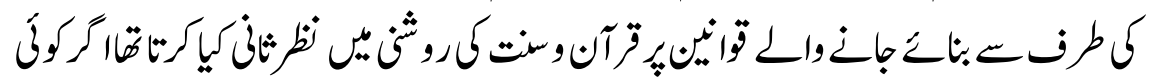

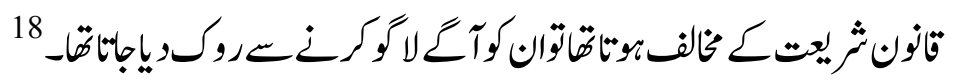

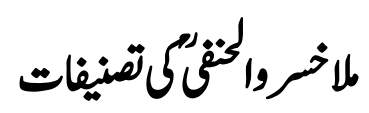

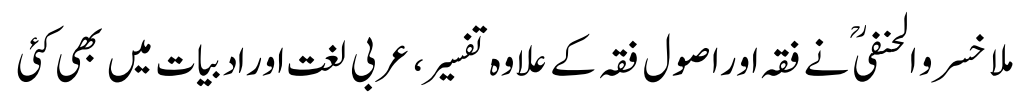

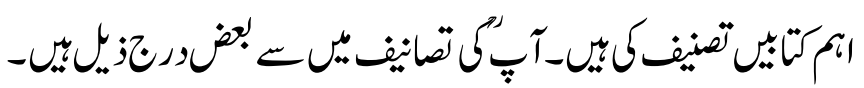




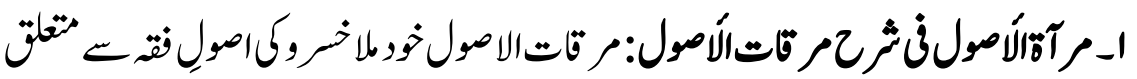

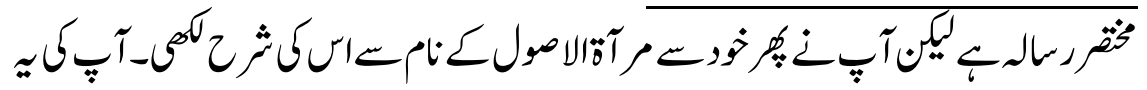

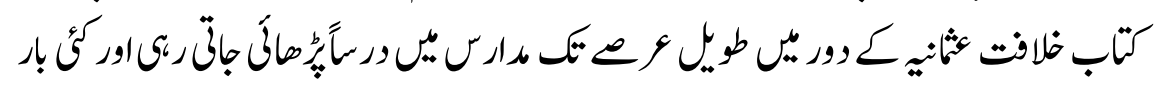

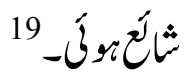

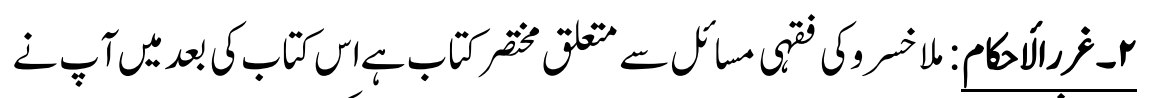

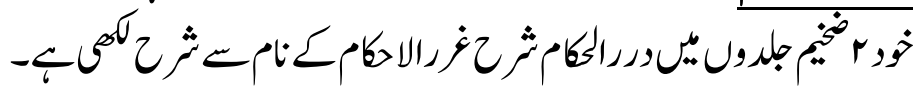

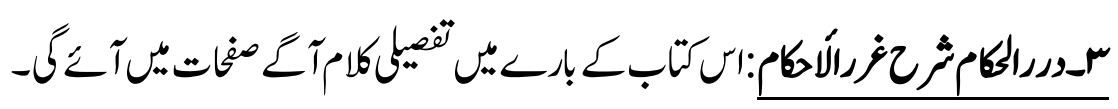

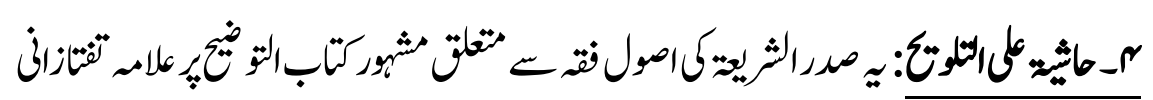

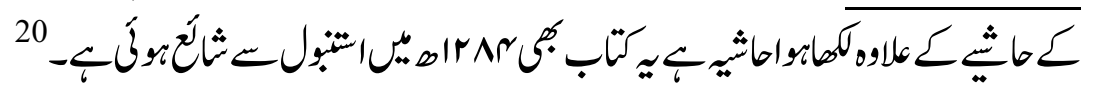

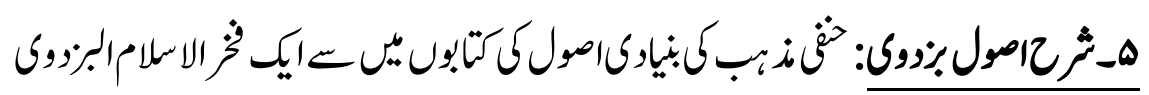

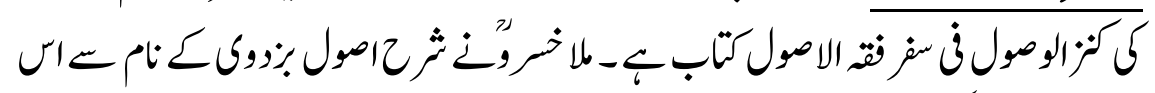

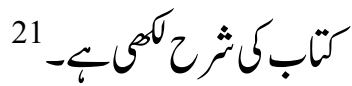

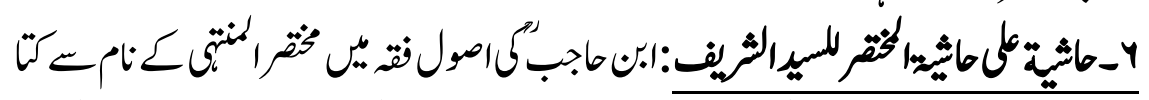

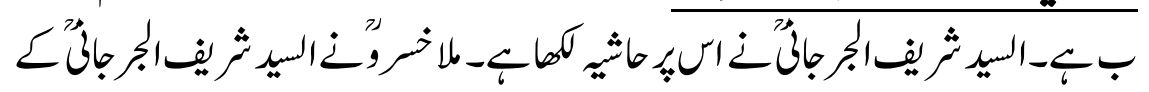

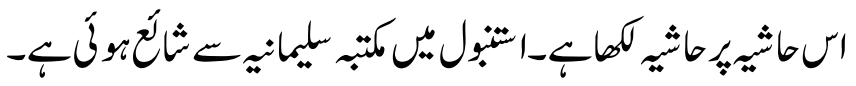

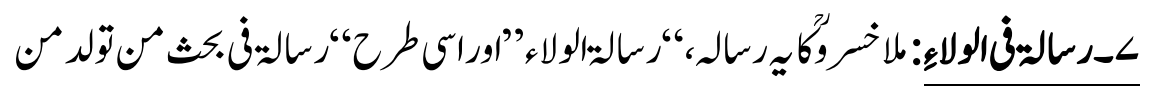

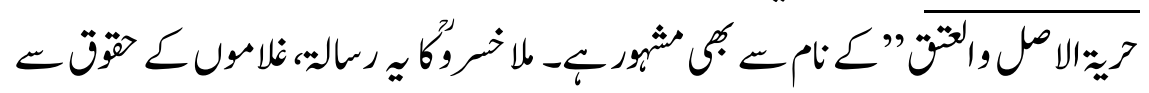

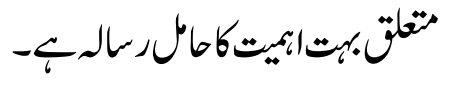

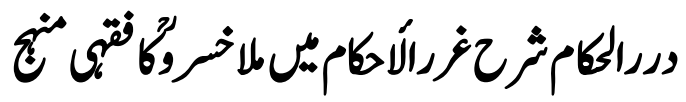

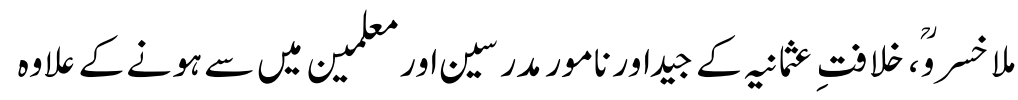

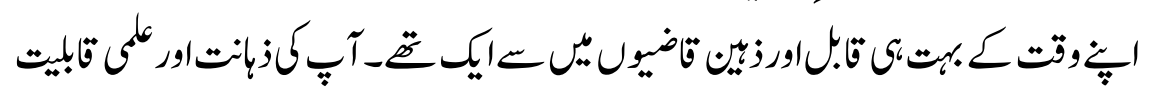




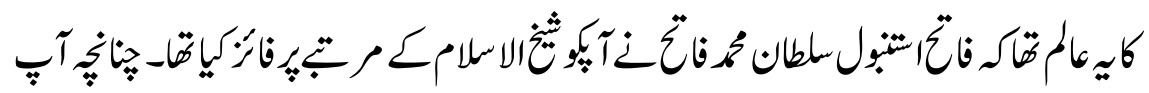

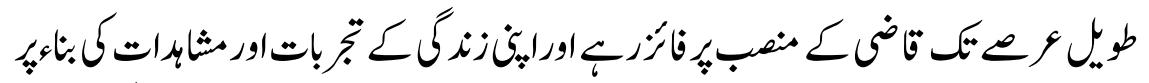

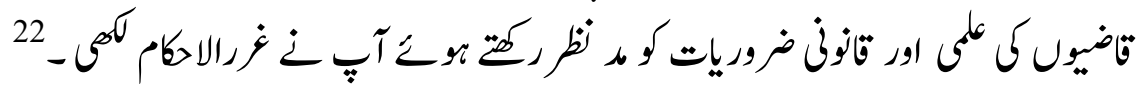

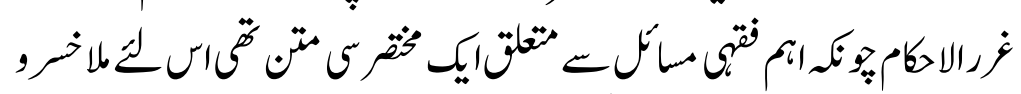

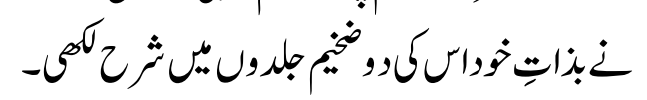

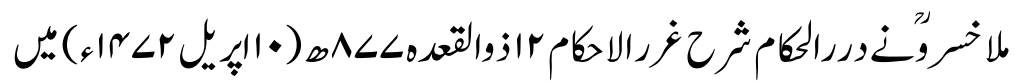

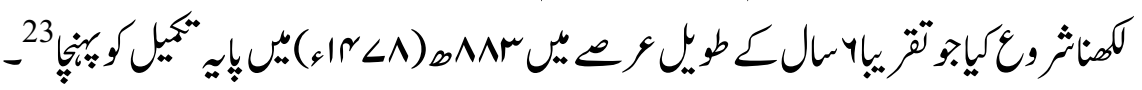

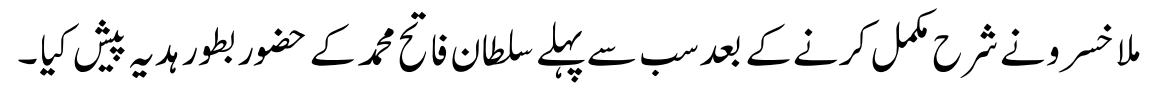

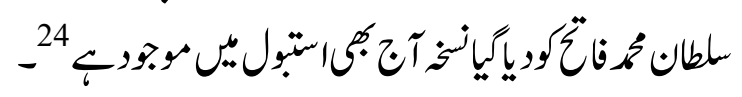

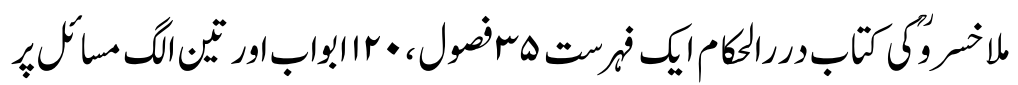

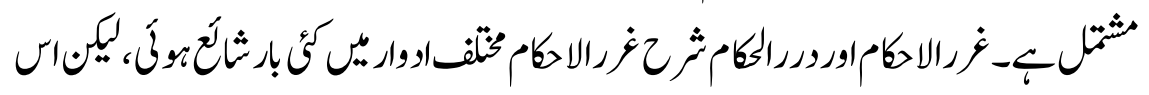

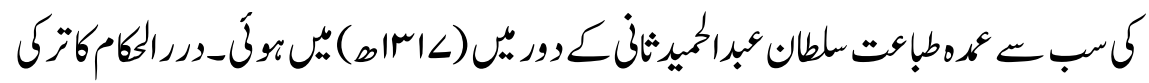

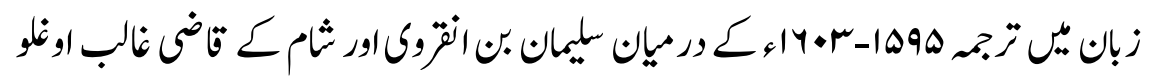

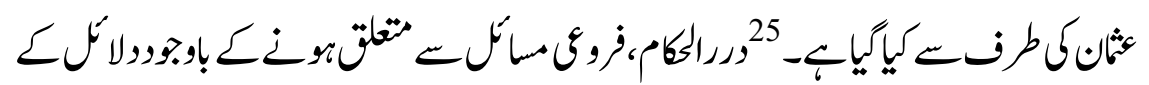

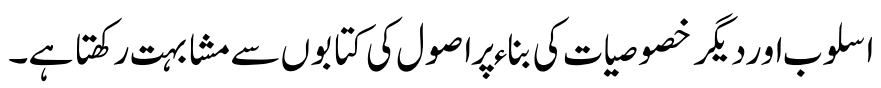

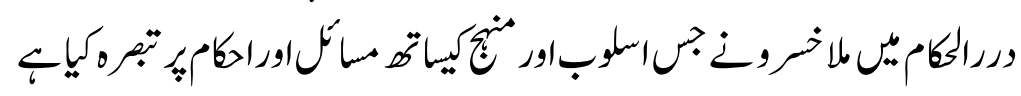

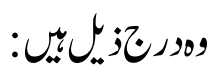

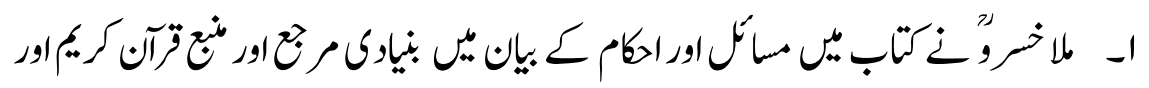

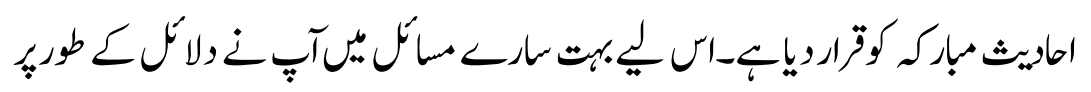

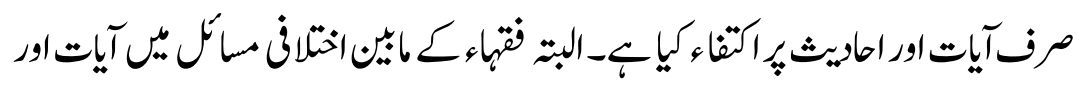

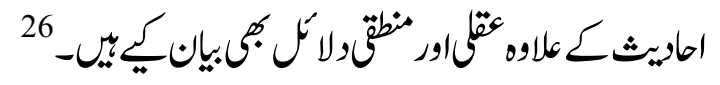




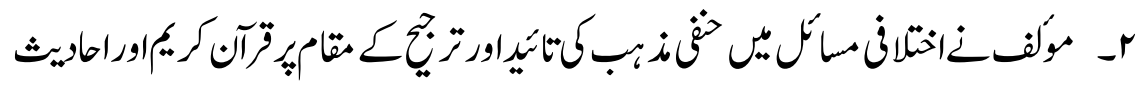

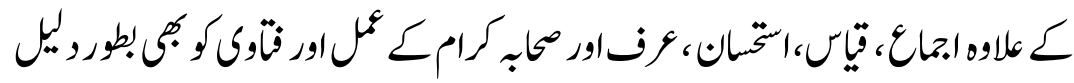

$$
27 \text {;كركي }
$$

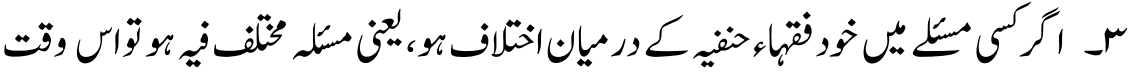

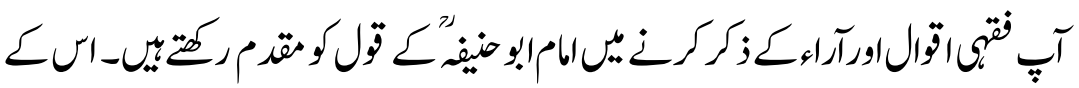

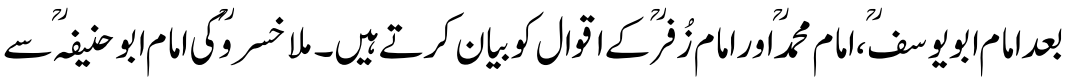

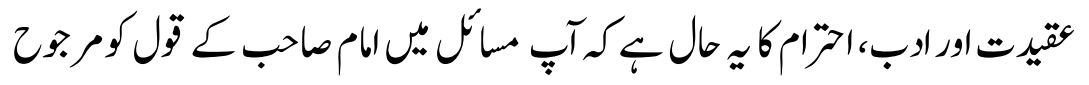

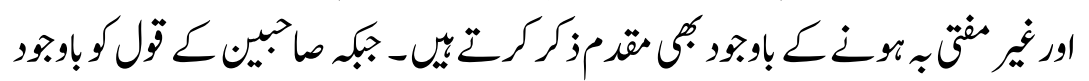

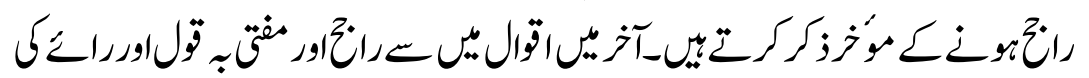

$$
\text { وضاحت كركتئ- } 28
$$

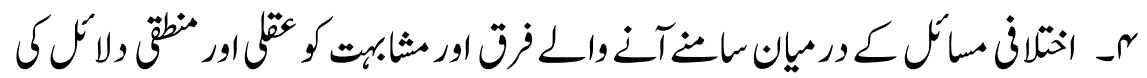

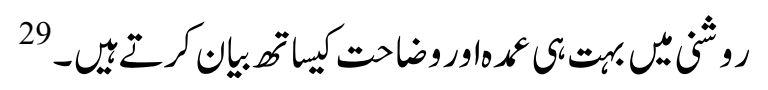

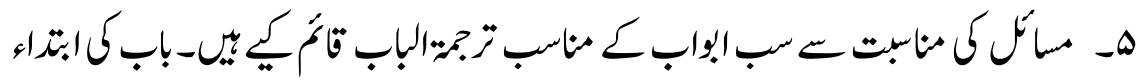

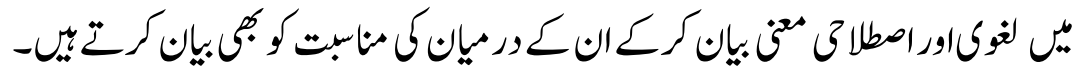

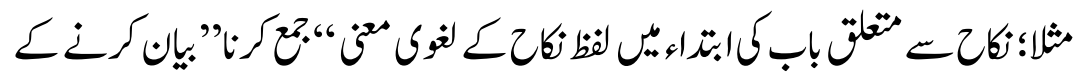

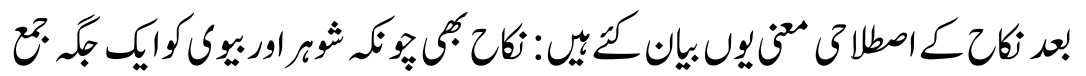

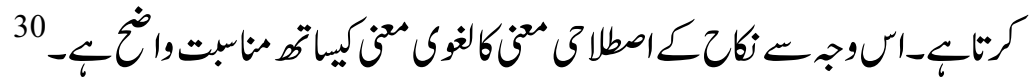

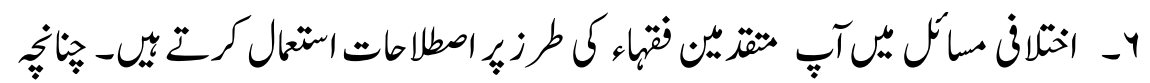

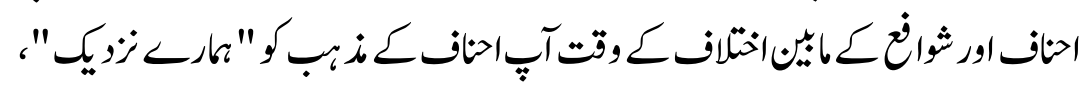

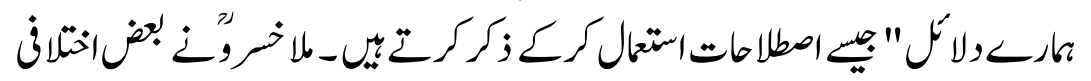

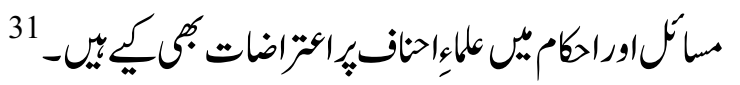

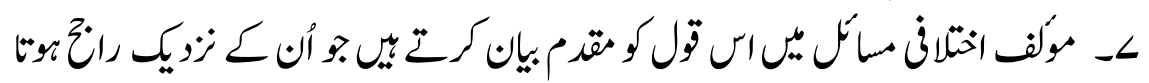




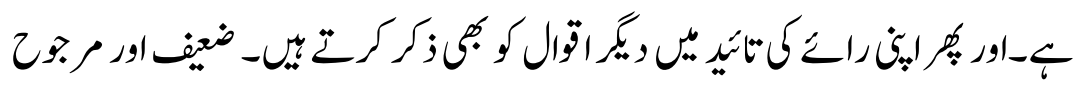

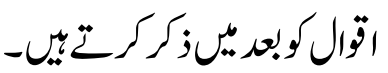

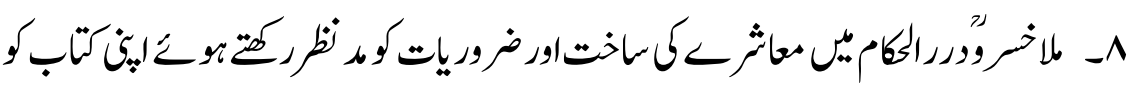

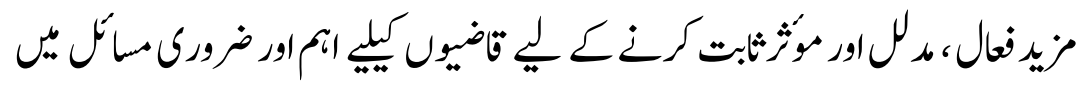

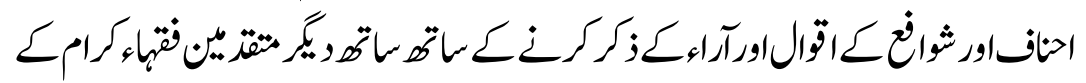

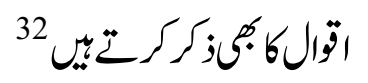

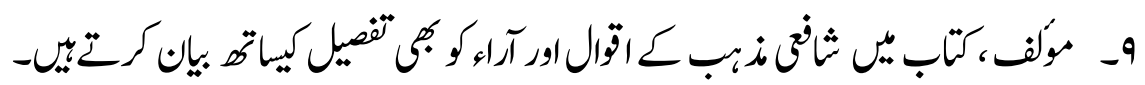

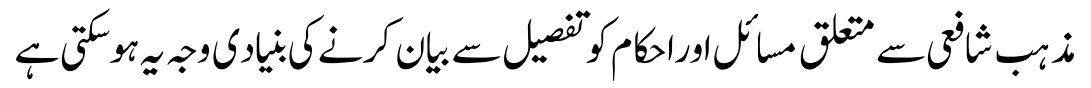

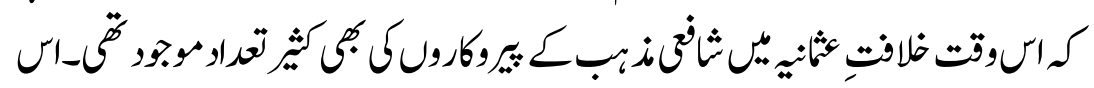

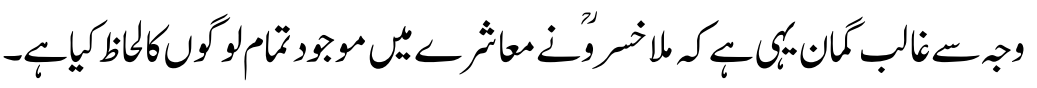

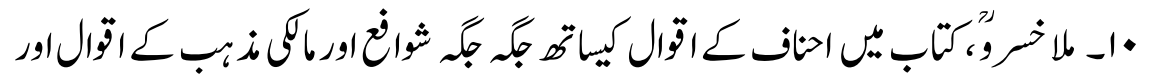

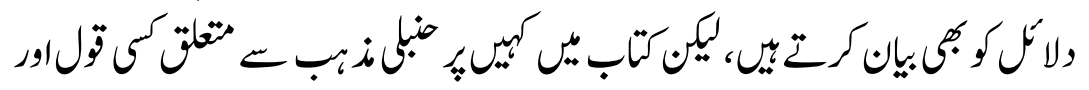

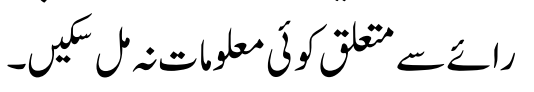

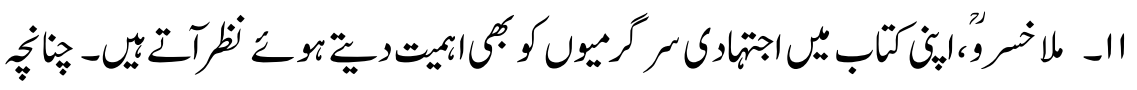

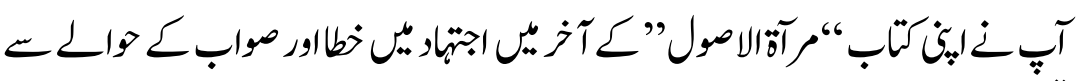

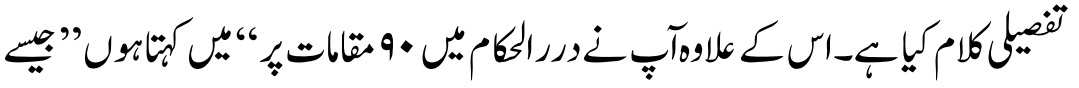

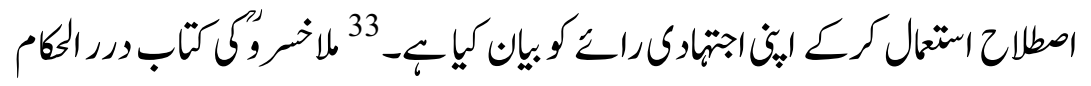

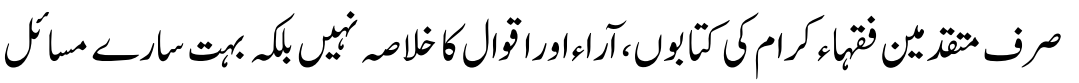

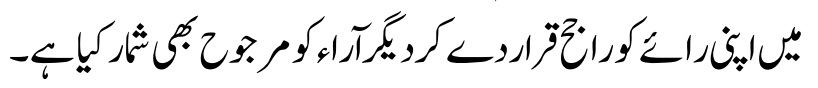

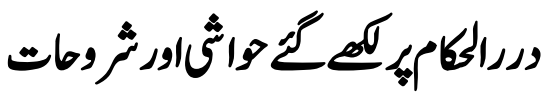

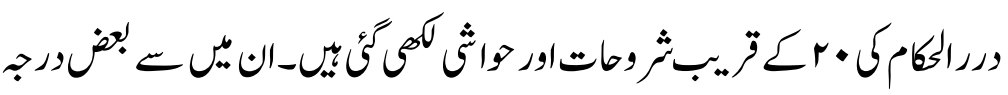
;ئيّ: 


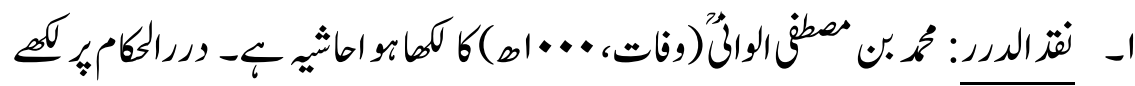

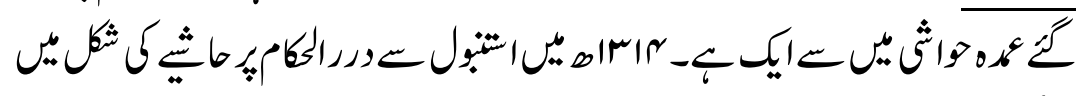

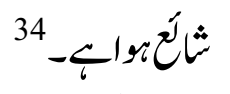

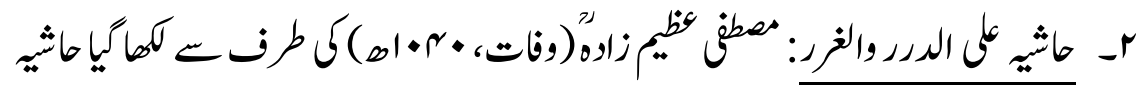

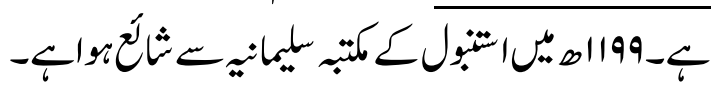

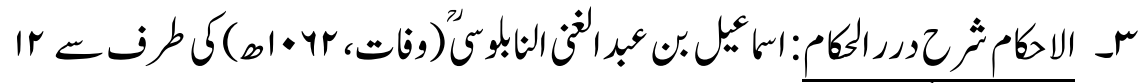

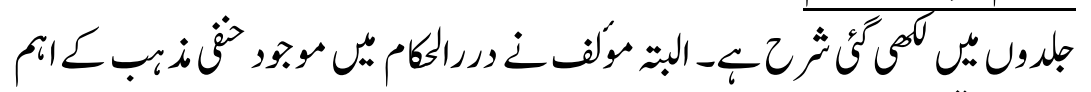

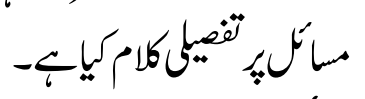

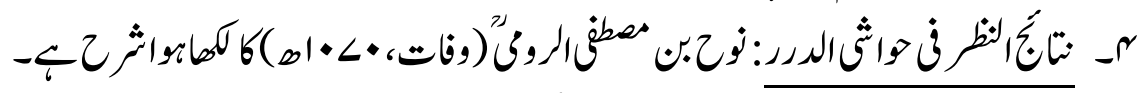

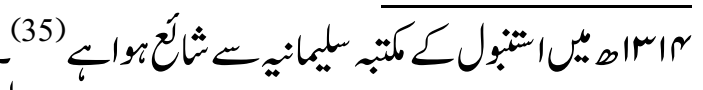

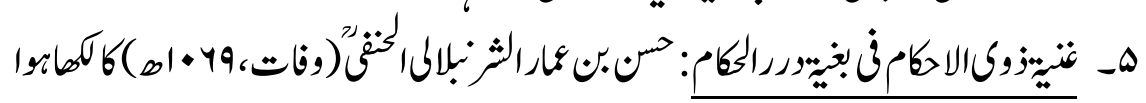

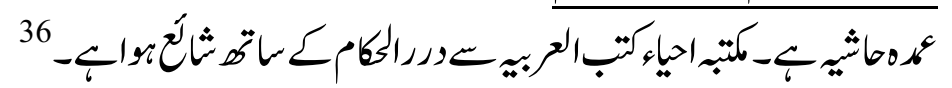

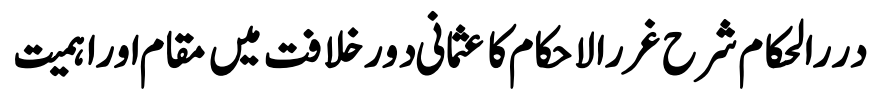

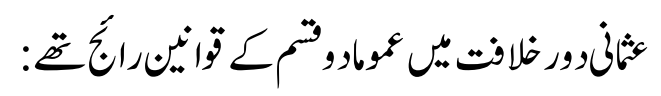

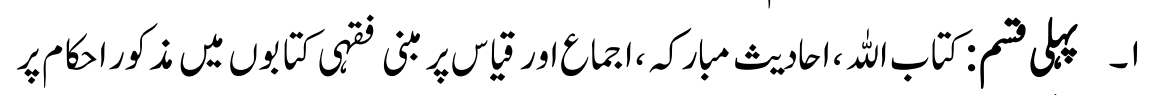

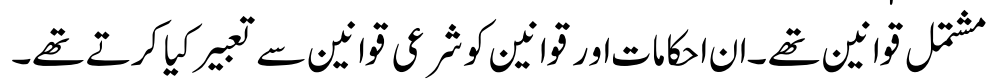

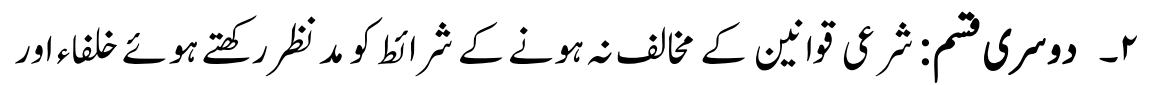

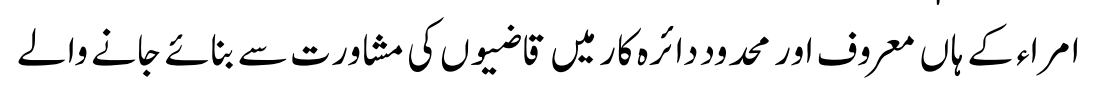

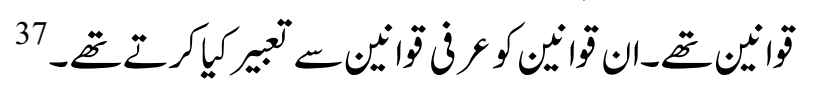

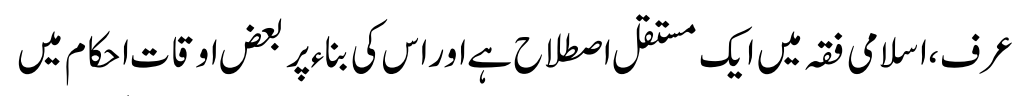

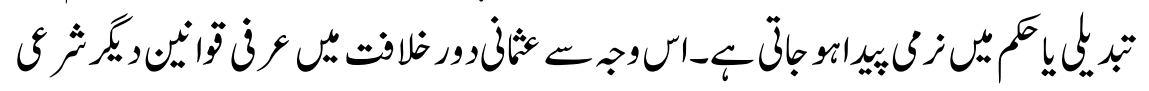




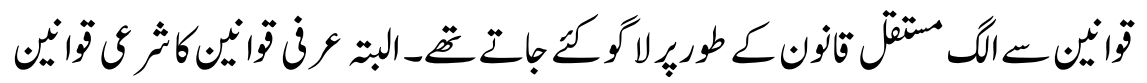

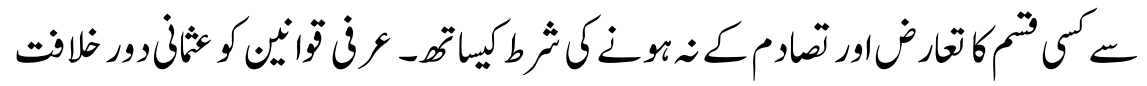

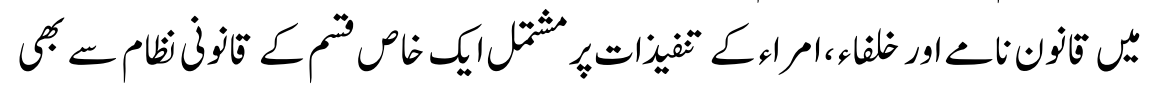

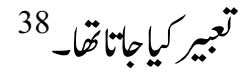

\section{خلام'كث}

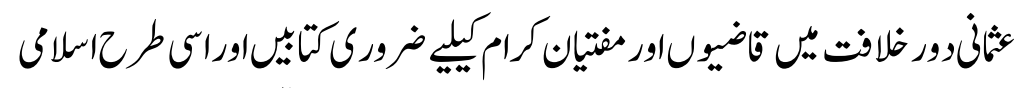

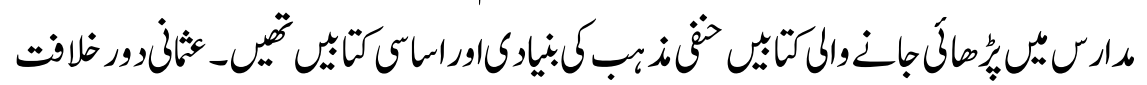

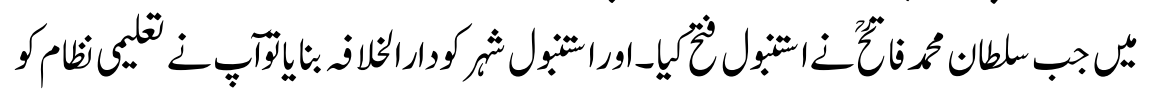

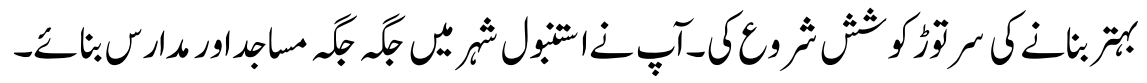

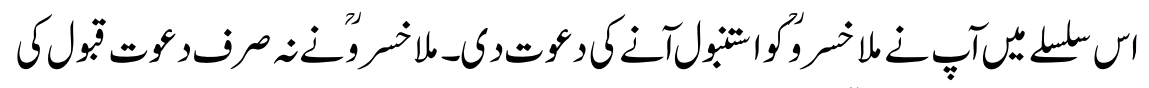

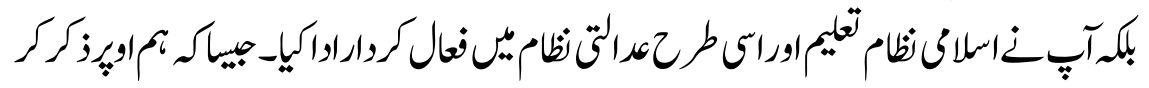

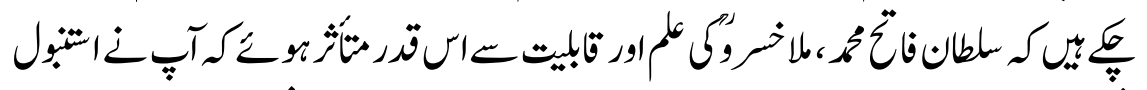

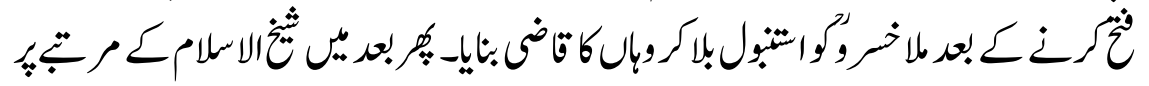

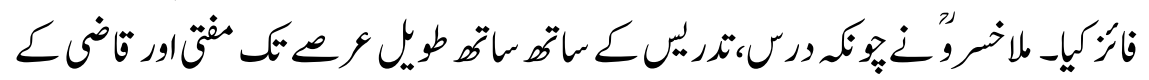

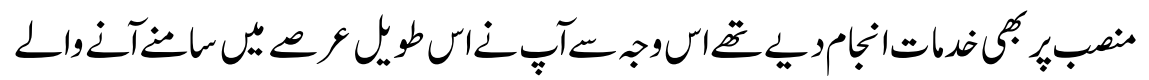

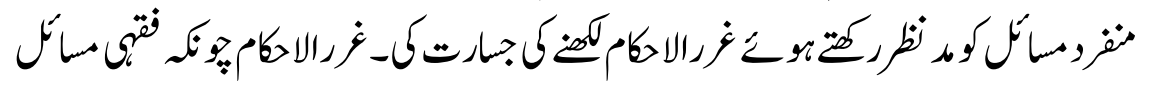

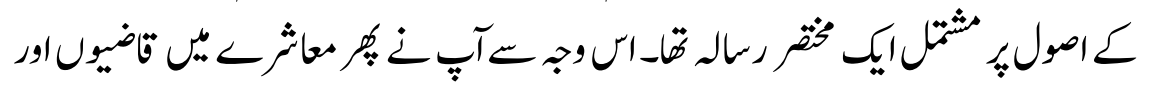

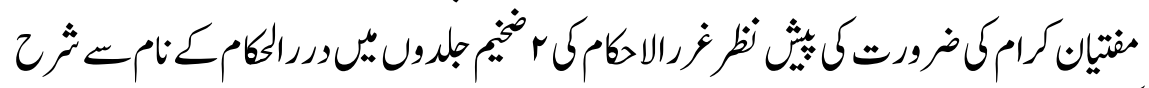

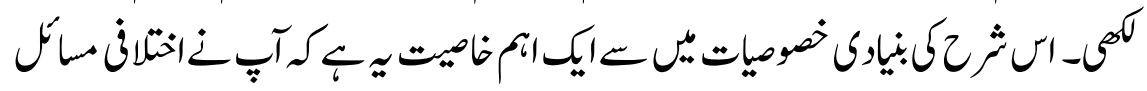

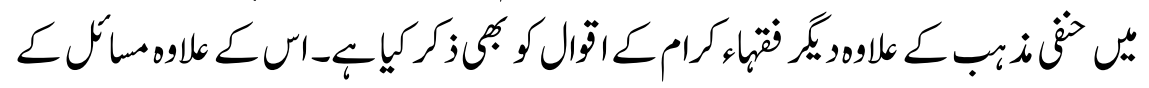

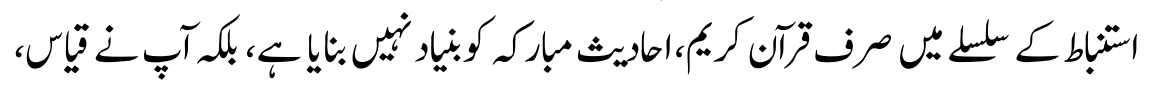




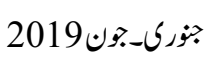

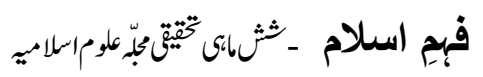

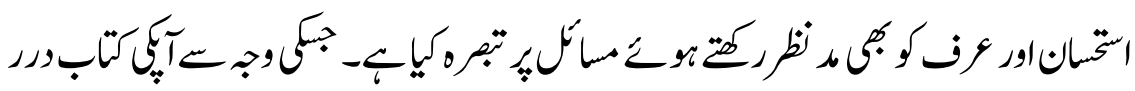

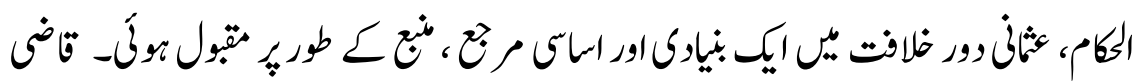

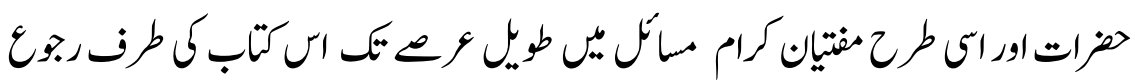

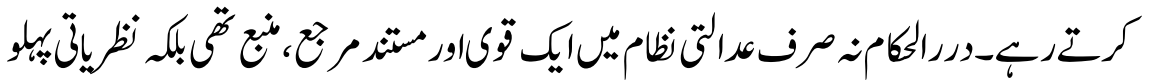

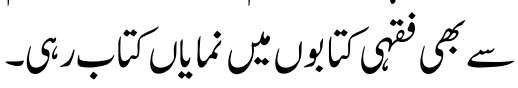

المصاوروالمرانع

1

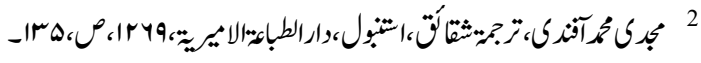

每 3

每

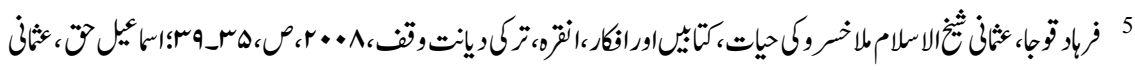

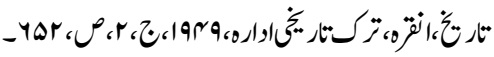

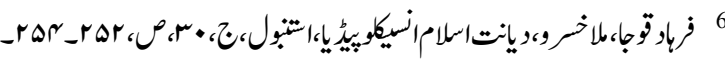

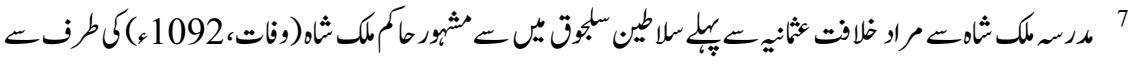

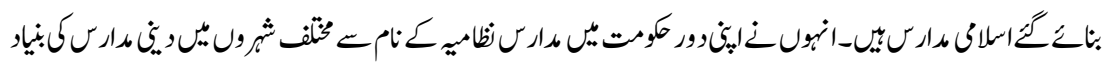

$-3$

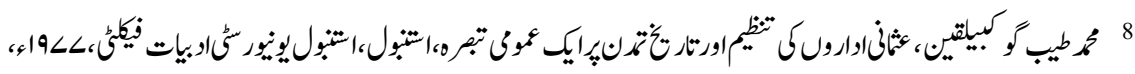

$-1<r \cdot c^{0}$

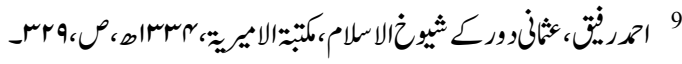

10

11

年

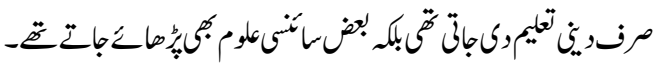

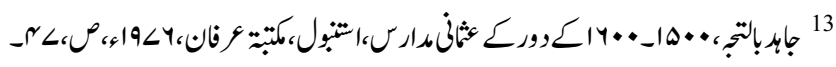

13 


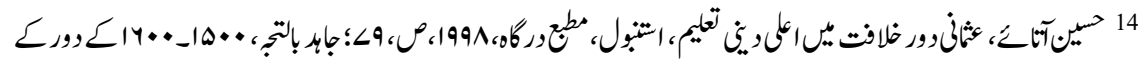

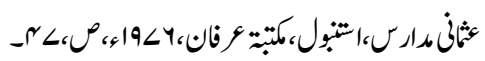

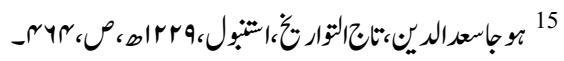

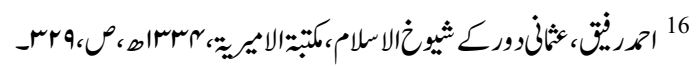

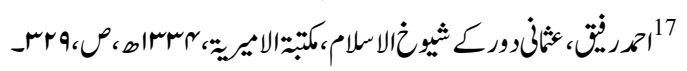

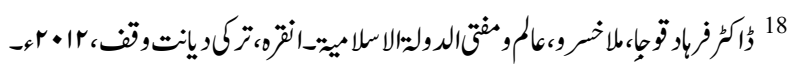

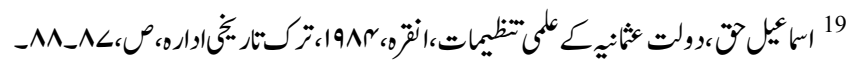

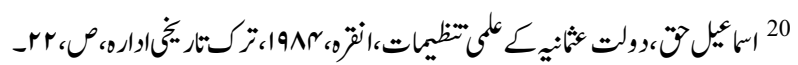

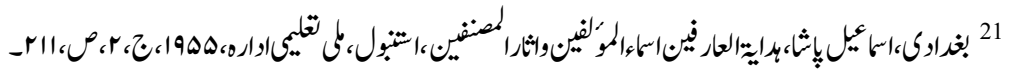

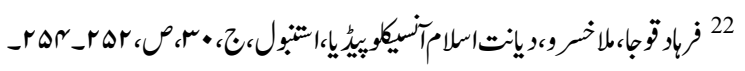

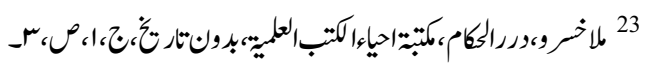

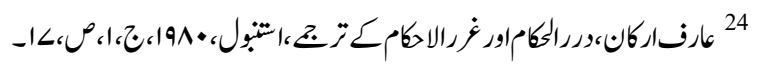

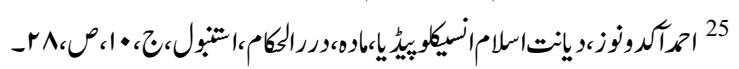

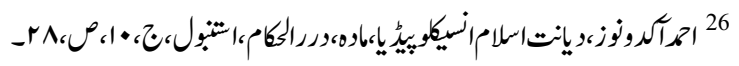

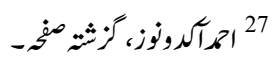
28

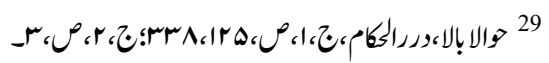
30 每 32

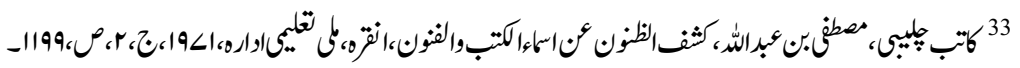
落

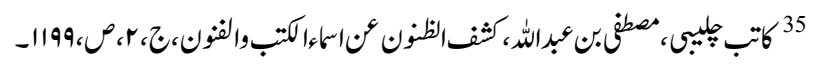

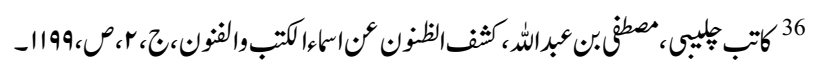

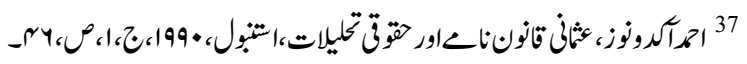

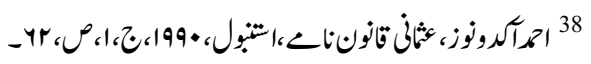

